\title{
Genetic Testing for Early Detection of Individuals at Risk of Coronary Heart Disease and Monitoring Response to Therapy: Challenges and Promises
}

\author{
H. Robert Superko - Robert Roberts - Arthur Agatston - Stephen Frohwein • \\ Jason S. Reingold • Thomas J. White • John J. Sninsky • Basil Margolis • \\ Kathryn M. Momary • Brenda C. Garrett • Spencer B. King III
}

Published online: 10 August 2011

(C) The Author(s) 2011. This article is published with open access at Springerlink.com

\begin{abstract}
Coronary heart disease (CHD) often presents suddenly with little warning. Traditional risk factors are inadequate to identify the asymptomatic high-risk individuals. Early identification of patients with subclinical coronary artery disease using noninvasive imaging modalities would allow the early adoption of aggressive preventative interven-
\end{abstract}

H. R. Superko $(\bowtie) \cdot$ T. J. White $\cdot$ J. J. Sninsky

Celera Corporation,

1401 Harbor Bay Parkway,

Alameda, CA 94502, USA

e-mail: HighHDL@mac.com

T. J. White

e-mail: Thomas.White@celera.com

J. J.Sninsky

e-mail: John.Sninsky@celera.com

\section{R. Roberts}

Ruddy Canadian Cardiovascular Genetics Centre,

University of Ottawa Heart Institute,

40 Ruskin Street,

Ottawa, ON K1Y 4W7, Canada

e-mail: rroberts@ottawaheart.ca

\section{A. Agatston}

South Beach Preventive Cardiology,

1691 Michigan Ave, \#500,

Miami Beach, FL 33139, USA

e-mail: Arthuragatston@southbeachdietlp.com

H. R. Superko - S. Frohwein · J. S. Reingold • B. Margolis •

K. M. Momary $\cdot$ S. B. King III

Saint Joseph's Hospital of Atlanta,

665 Peachtree Dunwoody Road, N.E.,

Atlanta, GA 30342, USA

S. Frohwein

e-mail: SFrohwein@sjha.org tions. Currently, it is impractical to screen the entire population with noninvasive coronary imaging tools. The use of relatively simple and inexpensive genetic markers of increased CHD risk can identify a population subgroup in which benefit of atherosclerotic imaging modalities would be increased despite nominal cost and radiation exposure. Additionally, genetic

\author{
J. S. Reingold \\ e-mail: jreingold@gmail.com \\ B. Margolis \\ e-amail: basilMargolis@gmail.com
}

K. M. Momary

e-mail: MOMARY_KM@mercer.edu

S. B. King III

e-mail: sking@sjha.org

H. R. Superko $\cdot$ K. M. Momary

College of Pharmacy and Health Sciences, Mercer University, 3001 Mercer University Drive,

Atlanta, GA 30341-4415, USA

H. R. Superko • B. C. Garrett

Cholesterol, Genetics, and Heart Disease Institute,

40 Bear Paw,

Portola Valley, CA 94028, USA

B. C. Garrett

e-mail: Superbrenda@mac.com

S. B. King III

Emory University,

Atlanta, GA, USA 
markers are fixed and need only be measured once in a patient's lifetime, can help guide therapy selection, and may be of utility in family counseling.

Keywords Genetic $\cdot$ Risk factor Imaging - Coronary heart disease $\cdot$ Screening

\section{Introduction}

The genetic revolution for some individuals has yet to begin whereas for others it came and was a disappointment. Although such a statement may be a cliché, it does not reflect the recent genetic efforts of the scientific community. The quest to elucidate the genetic factors predisposing to common diseases is based on well-founded progress. The revolution did not gain momentum until 2005, and in 6 years the progress has been nothing short of remarkable. The high-throughput microarray platforms employed to perform genome-wide association studies (GWAS) have already provided more data than can be currently appraised or applied [1]. Nearly 1000 loci have been shown to associate with common diseases [2]. The critics are quick to indicate the effect of any one locus is small and unlikely to revolutionize therapy or usher in the era of personalized medicine. Cholesterol has been known to be a risk factor for coronary artery disease (CAD) since the 1950s. The first specific drugs to lower cholesterol were produced in 1987, yet we are still working to overcome barriers that prevent such testing and therapy for primary and secondary prevention. This is just the beginning of the genetic revolution and its success is likely to inspire and accelerate future efforts. First, in regard to heart disease, GWAS have revealed that there are many mechanisms inducing CAD and myocardial infarction (MI) independent of known traditional risk factors [3]. Second, there are many more genetic factors yet to be identified for heart disease and other common diseases. Third, we can expect new drugs to be developed as a result of targeting these new mechanisms. Fourth, now is the time to acquire the education and infrastructure to properly apply genetic testing and prevention.

It has been stated that heart disease can be eliminated in this century [4]. This exuberant statement was stimulated by the observation that most types of heart disease are preventable. Clinical trials have shown that modulating current risk factors prevents $30 \%$ to $40 \%$ of heart disease [5]. Epidemiology and family studies have long documented that approximately $50 \%$ of susceptibility for heart disease is genetic [6]. We should hope and prepare for the day when these genetic factors are elucidated. Comprehensive prevention and treatment will be possible only if we know the genetic predisposition [7]. There are currently over 30 loci proven to be associated with increased risk for
CAD [8]. While caution is advised, there are costs to delaying the implementation of genetic testing and it may be productive to consider provisional approaches [9]. There are some benefits to be derived currently from testing for genetic predisposition. This review is a description of examples illustrating this benefit.

Atherosclerosis is often a slow-moving and silent disease until the eventual development of a sudden coronary event or the appearance of symptoms of myocardial ischemia. Sixty-seven percent of out-of-hospital emergency medical services-treated cardiac arrests have no symptoms within 1 hour of death [10]. However, many individuals develop coronary atherosclerosis and lead active lives, eventually succumbing to a fatal disorder not necessarily related to coronary atherosclerosis. The relatively recent concept of plaque instability as the acute etiology of a clinical event is now embraced by the medical community and highlights the important difference between the presence of coronary atherosclerosis and a clinical event [11]. Nevertheless, the more atherosclerosis that is present in the coronary tree, the greater the likelihood that a clinical event will occur [12]. Thus, detection of evidence of coronary atherosclerosis prior to an event allows aggressive and individualized preventive measures to be taken that have the potential to significantly reduce the probability of future coronary events in a primary prevention population.

The approach embraced by the general medical community for primary prevention may be termed "treat by the numbers". As exemplified by the Adult Treatment Panel (ATP) III guidelines, blood lipid levels above a specific number are to be considered as reflecting increased risk and thus deserving of treatment [13]. Consequently, a number below the predefined level implies no increased risk and thus does not require treatment. This approach has encouraged physicians to simply assume elevated or normal risk based on statistical relations for an "average" individual and ignores the great heterogeneity in the human population. Indeed, it is established that most patients with coronary events would not fit into the average guidelines and thus would not have received aggressive risk management [13]. According to the ATP III guidelines, low-density lipoprotein cholesterol (LDL-C) reduction is the primary focus for risk reduction [14]. However, in a large study with 244,000 person-years of follow-up, it was reported that statin use in the primary prevention population did not significantly reduce all-cause mortality, nor was there any material relationship between mean LDL-C reduction and reduction in all-cause mortality [15•]. Although many statin-induced LDL-C reduction studies have demonstrated an approximately $27 \%$ relative risk reduction, this actually equates to only a 3.4\% absolute risk reduction and leaves many prevention patients at increased risk despite statin therapy [16]. 
The best predictor of an atherosclerotic cardiovascular event is the known presence of atherosclerosis. If a primary prevention patient is found to have atherosclerosis, they should be moved into the secondary prevention algorithm allowing for more aggressive preventive treatment strategies. One approach to this is to utilize noninvasive imaging to detect asymptomatic coronary atherosclerosis early. However, this approach has been criticized as exposing too many primary prevention patients to either increased personal expense or unnecessary radiation exposure to CT scanning, although both the amount of radiation and the cost have been decreasing with the use of state of the art equipment [17]. A potentially more efficient approach that could improve the risk/benefit ratio of noninvasive imaging would be to categorize the primary prevention population into higher and lower risk utilizing tools that improve upon standard risk factor assessment. One of these tools is the utilization of genetic risk markers either through phenotypic tests or genotypic tests. One of the most powerful tests is simply a family history of premature CHD; however, recent advances in the field of genetics allow more accurate assessment of CHD risk. Once the presence of atherosclerosis is identified through noninvasive imaging, genetic tests can also be utilized to help the clinician determine the most effective treatment for the individual patient [18].

Even though the promise of clinically useful genetic tests has been around for decades, a few relatively recent scientific breakthroughs have allowed the promise to become a reality. Although DNA was isolated by Miescher in 1869, and Watson and Crick received the Nobel Prize for elucidating the double helix in 1954, it was Kary Mullis' invention of the polymerase chain reaction in 1985, for which he shared the Nobel Prize in 1993, that catalyzed the field of human genetic research. In 2001, a draft sequence of the human genome was presented by both Venter and Collins that provided the road map for future research plans and discoveries [19, 20]. Most recently, the invention of "gene chip" technology has allowed 1 million single nucleotide polymorphisms (SNPs) to be assessed in each individual in an investigation and has spawned the GWAS approach [21]. Advances in the technology of genetic analysis have significantly reduced the cost to consumers and provide the opportunity of practical tests with clinical utility.

It has been stated that in order for predictive risk scores to be useful, "A distinction must be made between population and individual targeting for the evaluation and management of the CVD risk factor profile. ... In order to succeed, primary prevention strategies for individual patients should be simple and personal" [22]. Two clinically available tools to enhance "personalization" include genetic tests and noninvasive imaging for individual patient management.
Clinical utility of inherited cardiovascular risk testing currently exists utilizing both phenotypic and genotypic markers. These markers can improve the accuracy of CHD risk prediction, help in the selection of a treatment most likely to be successful, and be informative in family counseling [23]. One major impediment to widespread clinical adoption of this concept involves privacy issues. Privacy issues were addressed in the Federal genetic nondiscrimination bill (Genetic Information Nondiscrimination Act H.R. 493 of 2008), which was passed by both the House of Representatives and the US Senate on May 22, 2008, and signed into law by President George W. Bush.

This article addresses the utility of genetic tests to identify high-risk subgroups, discusses a sample of practical genetic tests that may guide risk prediction and treatment decisions, and raises the issue of combining genetic tests with noninvasive imaging to enhance identification of individuals at high risk for CHD.

\section{Detection of High-Risk Subgroups through Genetic Testing: $9 p 21$}

In 2007, the first common gene for coronary artery disease (9p21) was identified almost simultaneously by two separate groups using a GWAS [24, 25]. This polymorphism is located on the short arm (p) of chromosome 9 in the band region 2.1 and so it is referred to as $9 p 21$. In the Ottawa Heart Study, the initial mapping of $9 p 21$ was in an Ottawa population and it was subsequently confirmed in independent populations from Dallas, Houston, and Denmark for a total of 23,000 Caucasian subjects. The $9 p 21$ risk variant is very common, occurring in $75 \%$ of the Caucasian population, with $50 \%$ inheriting a single copy (heterozygous) and $25 \%$ two copies (homozygous). Individuals have an increased relative risk for CHD of about $40 \%$ and $20 \%$ for those with two or one copy of the $9 p 21$ variant, respectively. Perhaps the most exciting, unexpected bonus is that $9 p 21$ risk is independent of all known risk factors, namely, cholesterol, hypertension, diabetes or obesity. This clearly implies a novel, previously unknown pathway contributing to the genesis of atherosclerosis. Simultaneously, Helgadottir et al. [25] showed 9p21 was associated with a similar increased risk for MI.

Over the next 6 months, multiple studies throughout Europe involving over 65,000 individuals confirmed 9p21 to be a common risk factor for CHD in Caucasians [26-28]. Studies have also confirmed that $9 p 21$ has a similar frequency and increased risk for CHD Chinese [29], Korean/Japanese [30], and East Indian [31] populations. The $9 p 21$ variant does not appear to be associated with increased risk for CHD in individuals of African descent [31]. The $9 p 21$ locus has also been confirmed to be a risk 
factor for abdominal aortic aneurysms/intracranial aneurysms [32] and ischemic stroke [33]. Unfortunately, the $9 p 21$ region does not contain a protein coding gene but rather a long noncoding RNA (ANRIL) that presumably regulates other genes in a novel pathway predisposing to CHD. A recent study suggests ANRIL may mediate its risk for atherosclerosis through the interferon pathway [34]. Since the initial 9p21 study, over 30 genes have been identified and replicated in independent populations of large sample size to be associated with increased risk for CHD [8]. These risk loci were mapped in a discovery population of over 80,000 cases and controls and replicated in an independent population of over 50,000 . Most of these genes occur in the population with a frequency varying from $13 \%$ to $90 \%$ and are associated with a $6 \%$ to $20 \%$ increased risk of CHD per allele. Notably, the risk associated with most of these alleles is independent of traditional CHD risk factors. These studies were performed using the interchangeable phenotype of MI or coronary atherosclerosis and genotyped via GWAS using a microarray with over 2 million SNPs [35]. Recently, a locus was identified that is associated with increased risk for MI without any risk for atherosclerosis [36]. More specific phenotypes or sub-phenotypes for atherosclerosis are expected to emerge from these studies.

Most recently, the presence of the $9 p 21$ risk allele has been shown to improve standard risk prediction models. The Atherosclerosis Risk In Communities (ARIC) risk equation can be used to assess an individual's risk potential and includes a family history of heart disease. In 2009, Brautbar et al. [37•] showed that the addition of $9 p 21$ information to the ARIC risk score reclassified $32.9 \%$ of individuals into more accurate risk categories when in the two moderate-risk groups $(5 \%-10 \%$ and $10 \%-20 \%)$, and the reclassification index was improved in $45.1 \%$ in all risk groups (Table 1).

In 2010, Dandona et al. [38] reported that there was a strong direct association between the proportion of early onset three-vessel disease and the gene dose of $9 p 21$ (rs1333049). The authors concluded that given its $(9 p 21)$ ability to predict risk within a CHD population, genotyping $9 p 21$ may be useful not only in determining risk for development of disease but also for risk stratification among patients with documented CAD. This documented relationship between $9 p 21$ homozygosity and arteriographic severity suggests that noninvasive imaging of the coronary arteries may be most productive in $9 p 21$ homozygous subjects, who comprise approximately $25 \%$ of the general population.

The presence of the $9 p 21$ polymorphism does not guarantee the presence of CHD but represents an independent risk predictor that helps identify a group at higher risk than previously thought based on traditional risk factor assessment. This creates the opportunity to use genetic tests to identify individuals who are more likely to benefit from noninvasive imaging and helps improve the risk/benefit of CT scanning. Three factors contribute to this rationale approach to primary prevention screening. First, 9p21 identifies risk for CHD independent of traditional risk factors. Second, it has been reported that $9 p 21$ homozygous individuals have more severe coronary atherosclerosis anatomic CHD than others. Third, there remains some controversy regarding potential adverse effects of radiation exposure associated with widespread public screening with fast CT. Use of this once-in-a-lifetime genetic test helps to identify $25 \%$ of the primary prevention population that may benefit most from fast CT screening.

This approach to more accurate risk prediction has taken another step forward by utilizing a panel of SNP tests that capture a wider range of genetic variation [39]. Davies et al. [40] have reported that a collection of 12 SNPs, including 9p21, improves CHD prediction over and above traditional risk factors (Fig. 1). The incorporation of over 30 SNPs shown to increase risk for CHD should make for even greater predictability and risk stratification for patients being considered for cardiac imaging such as fast CT coronary angiography.

\section{Detection of High Risk Subgroups through Genetic Testing: $L P A$}

Unlike $9 p 21$, some genetic tests can identify a high-risk group but have a low population frequency. However, such tests may have clinical utility in the majority of the population that does not carry the polymorphism.

\begin{abstract}
Table 1 Reclassification of risk when predictive values of $9 p 21$ genotyping are added to the ARIC risk score in 998 subjects followed for a mean of 14.6 years
\end{abstract}

ARIC-Atherosclerosis Risk in Communities study

(Data from Brautbar et al. [37•].)

\begin{tabular}{llllll}
\hline \multirow{2}{*}{ ARIC 10-year risk } & \multicolumn{2}{l}{ ARIC 10-year risk } & \multirow{2}{*}{ Reclassified, $n$ (\%) } \\
\cline { 2 - 5 } & $0 \%-5 \%$ & $5 \%-10 \%$ & $10 \%-20 \%$ & $>20 \%$ & \\
\hline $0 \%-5 \%$ & $97.8 \%$ & $2.2 \%$ & 0 & 0 & $87(2.2 \%)$ \\
$5 \%-10 \%$ & $7.9 \%$ & $82.9 \%$ & $9.2 \%$ & 0 & $319(17.1 \%)$ \\
$10 \%-20 \%$ & $0 \%$ & $7.0 \%$ & $84.2 \%$ & $8.8 \%$ & $382(15.8 \%)$ \\
$>20 \%$ & $0 \%$ & $0 \%$ & $10 \%$ & $90 \%$ & $185(10.0 \%)$ \\
Total, $n$ & 3936 & 1805 & 2394 & 1869 & \\
\hline
\end{tabular}




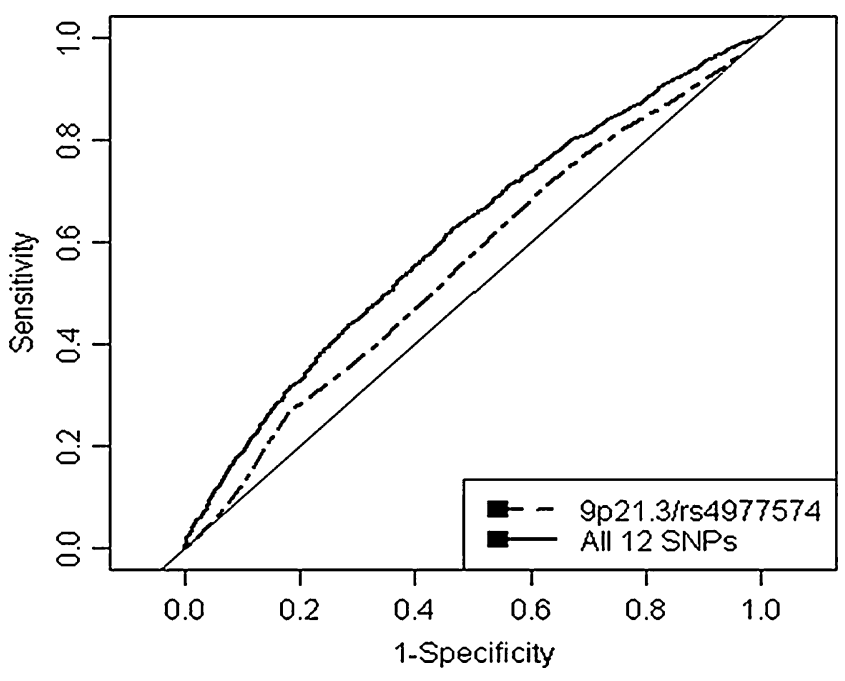

Fig. 1 A collection of 12 single nucleotide polymorphisms (SNPs), including $9 p 21$, improves coronary heart disease prediction over and above traditional risk factors. (From Davies et al. [40].)

One clinical question that continues to create difficulty for primary care physicians is the potential risk/benefit of daily aspirin use to reduce cardiovascular disease risk. Previous investigations have indicated that in the secondary prevention population, the benefit of daily aspirin and heart disease risk reduction outweighs the potential harm associated with daily aspirin use. However, in the primary prevention population the answer is less clear. The US Preventive Services Task force provided some guidance in 2009 by recommending cut-points based on the Framingham Risk Score (FRS) to identify patients who are more or less likely to derive heart disease or stroke prevention benefit from daily aspirin treatment [41]. The risk/benefit cut-point was defined by age and gender and was established at the FRS level at which the number of CHD events or strokes prevented equaled the number of gastrointestinal bleeds caused.

The LPA gene encodes the apolipoprotein(a) component of $\mathrm{Lp}(\mathrm{a})$, and a polymorphism in the protease-like region of the protein. It has been shown to provide useful information to help balance the risk/benefit ratio of daily aspirin use intended to reduce CHD risk. In the Women's Health study, 25,815 middle-aged women were randomized to aspirin or placebo. After 10 years of follow-up, women with the LPA risk variant in the placebo group experienced significantly more cardiovascular $(\mathrm{CV})$ events $(P<0.0005)$, but if women with the $L P A$ risk variant were randomized to aspirin, their $\mathrm{CV}$ event rate was equal to the non-carriers in both the placebo and aspirin group [42•]. Aspirin therapy had no effect on reducing CV events in the women without the LPA risk variant. This risk variant is found in approximately $4 \%$ of the population of European ancestry. However, the clinical utility may be in giving daily aspirin therapy advice to the $96 \%$ of people who are not carriers of the LPA risk variant, thus potentially reducing the risk of gastrointestinal compli- cations of long-term aspirin use. The number needed to treat to prevent one CV event in the Women's Health Study with aspirin was 625 in LPA non-carriers but only 37 in the women who carried the LPA risk variant.

\section{Detection of High Risk Subgroups through Genetic Testing: $A P O E$}

One of the most common genes affecting LDL-C levels codes for apoprotein $\mathrm{E}$, which has three major isoforms designated as E2, E3, and E4 [43]. Apo E with the common amino acid sequence is termed E3. Less common amino acid variants can result in E proteins termed E2 or E4. The most common variant, E3, has a frequency of approximately 0.78 , while $\mathrm{E} 4$ has a frequency of 0.15 , and $\mathrm{E} 2$ a frequency of 0.07. Apo E4 is a common contributor to elevated LDL-C and is found in approximately $25 \%$ of the population. The relatively rare Apo E2/2 genotype is the underlying cause for Type III hyperlipidemia. Comparison of individuals with the E3/2 versus E3/4 genotype revealed a difference in LDL-C levels of around $20 \mathrm{mg} / \mathrm{dL}$ or about $14 \%$ [44].

Apo $E$ genotyping can be beneficial in CHD risk prediction. A meta-analysis of Apo E genotype and CHD risk indicates a lower CHD risk for carriers of the E2 allele and slightly higher risk for carriers of the E4 allele [44]. Eighty-two studies were analyzed. The positive relationship between the E4 allele and blood LDL-C levels was confirmed and found to be significant and approximately linear. For the Apo E genotype, compared with E3/3, the odds ratio for CHD was 0.80 (95\% CI, 0.70-0.90) for E2/E2 individuals, and $1.06(95 \% \mathrm{CI}, 0.99-1.13)$ for $\mathrm{E} 4$ carriers in a study of 21,331 cases and 47,467 controls. In a GWAS, genetic variation in the Apo E gene locus was found to be significantly associated with variation in blood cholesterol measurements [45]. This common contributor to elevated LDL-C is one major factor responsible for the familial predisposition to CHD [46].

LDL-C reduction in response to statin therapy is quite variable and some, but not all studies, have reported a genotype-specific association and LDL-C response to statin treatment [47]. Subjects with the Apo E4 genotype tend to have higher baseline LDL-C and less reduction in LDL-C in response to statin treatment. PROVE IT-TIMI 22 was a prospective study in acute coronary syndrome patients randomized to $40 \mathrm{mg} / \mathrm{d}$ of pravastatin versus $80 \mathrm{mg} / \mathrm{d}$ of atorvastatin. In this investigation, subjects with the Apo E2 allele had the greatest LDL-C reduction and those with the Apo E4 allele the least LDL-C reduction in response to either statin [48]. The Apo $E$ genotype classification influenced the proportion of subjects who achieved a clinically meaningful LDL-C target, with more than $25 \%$ of E4 carriers failing to meet recommended LDL-C goals. 


\section{Genetic Tests to Help Guide Treatment}

Once CHD is diagnosed in a patient, either through noninvasive imaging or clinical criteria, the next medical issue is the selection of treatments that have the best chance for benefit while avoiding potential side effects in patients that may have less cardiovascular benefit. One such example is the KIF6 polymorphism, which identifies a patient subgroup that benefits the most from statin treatment in regard to clinical event reduction.

This common variant occurs in the kinesin-like protein 6 gene (KIF6), in which arginine replaces tryptophan (Trp719Arg) and is present in approximately $60 \%$ of the Caucasian population in sub-studies of major prospective trials [49•]. Relevant to treatment decisions, the statininduced clinical event reduction benefit has been found to be greater in carriers of the KIF6 risk variant compared to those who are not carriers in four major randomized clinical trials. Carriers of the KIF6 polymorphism have substantially fewer CHD events during pravastatin and atorvastatin therapy, whereas non-carriers do not despite similar ontreatment levels of LDL-C and C-reactive protein (CRP). In addition, the reduction of CHD events from intensive therapy (eg, high-dose atorvastatin) in the KIF6 polymorphism individuals is observed as early as 30 days after initiation of therapy. Consequently, assessment of KIF6 carrier status holds promise for stratification of coronary event risk and for selection of optimal therapy in primary and secondary CHD prevention. In randomized trials of pravastatin or atorvastatin therapy, the number needed to treat to prevent a single CHD event ranged from 10-20 for KIF6 carriers compared with 72 to 100 for non-carriers in the CARE, WOSCOPS, PROVE IT-TIMI 22, and PROSPER studies (Table 2). The clinical event differential response to statin therapy has not been reported in all studies. In the prematurely terminated JUPITER trial of rosuvastatin, low-risk KIF6 carrier individuals (hazard ratio [HR] $0.61 ; 95 \% \mathrm{CI}, 0.43-0.87)$ received the same clinical event reduction as the KIF6 non-carriers (HR 0.59; 95\% CI, 0.39-0.88) [50]. In a retrospective analysis of the Heart

Table 2 Number of patients needed to treat with a statin drug in four statin clinical trials to prevent one event over 2 years in patients determined to be KIF6 risk allele non-carriers and KIF6 risk allele carriers

\begin{tabular}{llll}
\hline Study & $\begin{array}{l}\text { All } \\
\text { patients, } n\end{array}$ & $\begin{array}{l}\text { KIF6 } \\
\text { non-carriers, } n\end{array}$ & $\begin{array}{l}\text { KIF6 } \\
\text { carriers, } n\end{array}$ \\
\hline CARE & 34 & 72 & 20 \\
WOSCOPS & 46 & $>100$ & 18 \\
PROSPER & 24 & 83 & 16 \\
PROVE IT & 16 & 125 & 10
\end{tabular}

(Data from Li et al. [49•].)
Protection Study, KIF6 carriers and non-carriers received similar clinical event reduction benefit from simvastatin treatment [51]. The KIF6 polymorphism may provide clinicians with a new tool with which to further personalize risk stratification and prediction of clinical event reduction benefit from statin therapy.

One medication that has been successfully utilized in National Institutes of Health-funded heart disease regression trials is nicotinic acid [52]. Although the physiologic benefit is documented and includes reduction in triglycerides, reduction in atherogenic small LDL, reduction in $\mathrm{Lp}(\mathrm{a})$, and increased high-density lipoprotein cholesterol (HDL-C) and HDL2, nicotinic acid remains underutilized in part due to annoying but tolerable side effects [53]. One polymorphism in the promoter region for hepatic lipase (HL) has been shown to identify a subgroup of CHD patients that respond better than others to nicotinic acid in regard to HDL-C and HDL2 elevation linked to improved arteriographic outcomes. In FATS, $51 \%$ of the population was homozygous for the HL514T polymorphism and they exhibited lower HDLC and HDL2 at baseline but much greater HDL-C and HDL2 increase following treatment [54]. Coronary stenosis change in this group was $-2.1 \%$ compared to $-1.1 \%$ in the heterozygous group and $+4.0 \%$ in the non-carrier group [54]. Use of relatively simple SNP testing can identify subgroups of patients that benefit more, or less, from specific drug therapy. Genetic testing and noninvasive imaging of preclinical atherosclerosis provides the clinician with two powerful tools with which to tailor their approach to the individual patient.

\section{Genetic Tests, Imaging, and Family Members}

Although it is accepted that a family history of CHD is a major risk factor for an individual patient, there is little guidance in the general medical community for the evaluation of family members of patients with "premature" CHD.

A family history of premature heart disease is one of the most powerful determinants of CHD risk and is independent of the common CHD risk factors such as smoking, hypertension, diabetes, and some lipids [55]. Retrospective studies have indicated that the risk of CHD in siblings of victims of premature CHD is approximately $50 \%$ for men and less for women [56]. In siblings of premature CHD patients, the risk of dying from CHD was 5.2 times higher than in a population without such a family history. The CHD risk associated with a family history of premature CHD is higher than the two- to threefold CHD risk associated with cigarette smoking [57].

Numerous prospective studies of the risk for CHD in firstdegree relatives have been conducted [58]. The age definition of "premature" is relative and perhaps misleading. In the Nurses Health Study, the risk for non-fatal MI was 5.0 if a family history of fatal CHD prior to age 60 years was 
present, but the risk was still 2.6 when a family history after 60 years of age was present. Thus, although the presence of CHD at an age $<60$ years indicated a very high risk, a history in a family member $>60$ years of age was still substantial and clinically informative. These prospective investigations indicate that the risk of MI is at least twofold greater if a family history of CHD is present and that the CHD risk is independent of classic CHD risk factors.

The use of noninvasive imaging has contributed to our understanding of the importance of family history in predicting CHD risk. The finding that the risk for a CHD event is approximately $50 \%$ in siblings of premature CHD patients has been reproduced utilizing noninvasive imaging [59]. In 1619 asymptomatic male subjects who underwent coronary artery calcium (CAC) testing, a family history of CHD in a first- or second-degree relative was reported to be highly predictive of a positive CAC score with odds ratios approaching 1.50 [60]. In a similar study of 8549 asymptomatic individuals, a family history of CHD in a parent increased the odds ratio to 1.3 in men and women, and a family history of CHD in a sibling increased the odds ratio to 2.3 [61]. The association of a family history of a positive CAC score is particularly powerful in siblings. Seventy-eight percent of individuals reporting a sibling with known CHD had a positive CAC score. With the emergence of noninvasive imaging modalities that do not expose the individual to ionizing radiation that can be performed in a mobile manner at a relatively nominal cost, the ability to screen large numbers of people will be possible. The emerging role of carotid and peripheral ultrasound techniques as well as the evaluation of endothelial function are two such modalities. Carotid intimal medial thickness measurements have been shown to not only identify individuals at higher risk for events, but there are emerging data that this modality can be utilized to follow preventive treatment strategies [62]. The measurement of endothelial dysfunction may allow the identification of younger groups of individuals at risk for events prior to visual identification of plaque using $\mathrm{CT}$ or ultrasound techniques [63]. Abnormal endothelial function is an early marker of subclinical atherosclerosis and increased cardiovascular risk. However, assessment has been limited to research laboratories under highly controlled conditions. Recently, peripheral amplitude tonometry has been validated as a novel technique for endothelial function assessment and suitable for use in ambulatory clinical practice [64].

The identification of individuals with the at-risk genotype is a one time test that can be performed early in the individuals life, with the potential for the noninvasive imaging modality to be utilized throughout the remainder of his/her life to follow and allow adjustments to the preventative treatment strategy. In this regard, noninvasive imaging screening in families with known CHD may be beneficial, particularly in family members with a pheno- typic or genotypic expression of CHD risk similar to the family member with known CHD.

\section{Conclusions}

Both genetic tests (phenotype and genotype) and noninvasive imaging modalities have been shown to identify groups of individuals at substantially increased risk for coronary events. Furthermore, genotype tests have demonstrated clinical utility in guiding therapies by identifying subgroups that have the best chance of achieving the desired outcome. Future utility may include professional groups that are at high CHD risk and presumably linked to their professional activities. Professional firefighters are known to be at a two- to threefold increased risk of CHD and recently it was reported that approximately one third have subclinical CHD not linked to traditional risk factors [65•]. Because family history is such a powerful predictor of CHD events, the combination of simple and relatively inexpensive genetic tests to clarify risk, followed by noninvasive imaging in the high-risk population, allows identification of a group most deserving of aggressive and individualized treatment.

Disclosure H.R. Superko is employed by Celera Corporation, and is a board member of CGHDI, a 501C3 nonprofit. R. Roberts is a consultant for Celera Scientific Advisory Committee. A. Agatston has nothing to disclose. S. Frohwein has nothing to disclose. J.S. Reingold has nothing to disclose. T.J. White is employed by Celera Corporation and owns stock/stock options in the company. J.J. Sninsky is employed by Celera Corporation and owns stock/stock options in the company. B. Margolis is a consultant for Celera Corporation and has received honoraria for speaking from the Berkeley Heart Lab. K.M. Momary has received grants from Pfizer and honoraria from Sanofi-Aventis and Novartis. B.C. Garrett is a lay board member of the SHAPE Society but receives no compensation for the position and is also married to H.R. Superko. S.B. King has received a grant from FEMA, is a consultant for Celonova Biosciences, has received payment from the Network for Continuing Medical Education for development of educational presentations, and is on Data Safety Monitoring Boards for Merck \& Co., Wyeth Pharmaceuticals, and nContact Surgical

Open Access This article is distributed under the terms of the Creative Commons Attribution Noncommercial License which permits any noncommercial use, distribution, and reproduction in any medium, provided the original author(s) and source are credited.

\section{References}

Papers of particular interest, published recently, have been highlighted as:

\section{- Of importance}

1. Roberts R. Personalized medicine: a reality within this decade. J Cardiovasc Trans Res. 2008;1:11-6. 
2. Kaiser J. The genome project: what will it do as a teenager? Science. 2011;660.

3. Evans JP, Meslin EM, Marteau TM, Caulfield T. Deflating the genomic bubble. Science. 2011;331:861-2.

4. Yusuf S, Hawken S, Ounpuu S, et al. Effect of potentially modifiable risk factors associated with myocardial infarction in 52 countries (the INTERHEART study case-control study). Lancet. 2004;364:937-52.

5. Wald NJ, Law MR. A strategy to reduce cardiovascular disease by more than $80 \%$. Br Med J. 2003;326:1419-23.

6. Chan L, Boerwinkle E. Gene-environment interactions and gene therapy in atherosclerosis. Cardiol Rev. 1994;2:130-7.

7. Roberts R, Stewart A. Personalized medicine: a future prerequisite for the prevention of coronary artery disease. Am Heart J. 2006;4:222-7.

8. Schunkert H, et al. Large-scale association analysis identifies 13 new susceptibility loci for coronary artery disease. Nat Genet. 2011;(In Press).

9. Green ED, Guyer MS, National Human Genome Research Institute. Charting a course for genomic medicine from base pairs to bedside. Nature. 2011;470:204-13.

10. Müller D, Agrawal R, Arntz HR. How sudden is sudden cardiac death? Circulation. 2006;114:1146-50.

11. Fuster V, Badimon L, Badimon JJ, Chesebro JH. The pathogenesis of coronary artery disease and the acute coronary syndromes (2). NEJM. 1992;326:310-8.

12. Budoff MJ, Gul KM. Expert review on coronary calcium. Vasc Health Risk Manag. 2008;4:315-24.

13. Akosah KO, Schaper A, Cogbill C, Schoenfeld P. Preventing myocardial infarction in the young adult in the first place: how do the National Cholesterol Education Panel III guidelines perform? J Am Coll Cardiol. 2003;4:1475-9.

14. NCEP ATP-III. Expert panel on detection, evaluation, and treatment of high blood cholesterol in adults. Executive summary of the third report of the National Cholesterol Education Program (NCEP) expert panel on detection, evaluation, and treatment of high blood cholesterol in adults (adult treatment panel III). JAMA. 2001;285:2486-97.

15. - Ray KK, Seshasai SR, Erqou S, Sever P, Jukema JW, Ford I, Sattar N. Statins and all-cause mortality in high-risk primary prevention: a meta-analysis of 11 randomized controlled trials involving 65,229 participants. Arch Intern Med. 2010;170:102431. This article reports the lack of a reduction in all-cause mortality with statin therapy in primary prevention.

16. Superko HR, King 3rd S. Lipid management to reduce cardiovascular risk: a new strategy is required. Circulation. 2008;117:560 8.

17. Tsalafoutas IA, Koukourakis GV. Patient dose considerations in computed tomography examinations. World J Radiol. 2010;2:262-8.

18. Wilffert B, Swen J, Mulder H, Touw D, Maitland-Van derZee AH, Deneer $\mathrm{V}$, et al. From evidence based medicine to mechanism based medicine. Reviewing the role of pharmacogenetics. Int $\mathrm{J}$ Clin Pharm. 2011;33:3-9.

19. Venter JC, Adams MD, Myers EW, et al. The sequence of the human genome. Science. 2001;291:1304-51.

20. Lander ES, Linton LM, Birren B, Nusbaum C, et al. Initial sequencing and analysis of the human genome. Nature. 2001;409:860-921.

21. Lettre G, Palmer CD, Young T, et al. Genome-wide association study of coronary heart disease and its risk factors in 8,090 African Americans: the NHLBI CARe Project. PLoS Genet. 2011;7:e1001300.

22. Fuster V. Are predictive risk scores useful? Nat Rev Cardiol. 2009;8:493.

23. Cirino AL, Ho CY. Genetic testing in cardiac disease: from bench to bedside. Nat Clin Pract Cardiovasc Med. 2006;3:462-3.
24. McPherson R, Pertsemlidis A, Kavaslar N, et al. A common allele on chromosome 9 associated with coronary heart disease. Science. 2007;316:1488-91.

25. Helgadottir A, Thorleifsson G, Manolescu A, et al. A common variant on chromosome 9p21 affects the risk of myocardial infarction. Science. 2007;316:1491-3.

26. Wellcome Trust Case Control Consortium. Genome-wide association study of 14,000 cases of seven common diseases and 3,000 shared controls. Nature. 2007;447:661-78.

27. Samani NJ, Erdmann J, Hall AS. Genomewide association analysis of coronary artery disease. NEJM. 2007;357:443-53.

28. Broadbent HM, Peden JF, Lorkowski S, et al. Susceptibility to coronary artery disease and diabetes is encoded by distinct, tightly linked SNPs in the ANRIL locus on chromosome 9p. Hum Mol Genet. 2008;17:806-14.

29. Kotani K, Fujiwara S, Tsuzaki K, et al. An association between angiotensin II type 2 receptor gene $\mathrm{A} / \mathrm{C} 3123$ polymorphism and glycemic control marker in a general Japanese population. Mol Biol Rep. 2009;36:9917-20.

30. Hinohara K, Nakajima T, Takahashi M, et al. Replication of the association between a chromosome 9 p21 polymorphism and coronary artery disease in Japanese and Korean populations. J Hum Genet. 2008;53:357-9.

31. Assimes T, Knowles JW, Basu A, et al. Susceptibility locus for clinical and subclinical coronary artery disease at chromosome 9p21 in the multi-ethnic ADVANCE study. Hum Mol Genet. 2008;17:2320-8.

32. Helgadottir A, Thorleifsson G, Magnusson KP, et al. The same sequence variant on 9p21 associates with myocardial infarction, abdominal aortic aneurysm and intracranial aneurysm. Nat Genet. 2008;40:217-24.

33. Matarín M, Brown WM, Scholz S, et al. A genome-wide genotyping study in patients with ischaemic stroke: initial analysis and data release. Lancet Neurol. 2007;6:414-20.

34. Harmismendy O, Notani D, Song X, et al. 9p21 DNA variants associated with coronary artery disease impair interferon-y signaling response. Nature. 2011;470:264-8.

35. Preuss M, König IR, Thompson JR, Erdmann J, Absher D, Assimes TL, Blankenberg S, Boerwinkle E, Chen L, Cupples LA, Hall AS, Halperin E, Hengstenberg C, Holm H, Laaksonen R, Li M, März W, McPherson R, Musunuru K, Nelson CP, Burnett MS, Epstein SE, O'Donnell CJ, Quertermous T, Rader DJ, Roberts R, Schillert A, Stefansson K, Stewart AF, Thorleifsson G, Voight BF, Wells GA, Ziegler A, Kathiresan S, Reilly MP, Samani NJ, Schunkert H, CARDIoGRAM Consortuim. Design of the coronary artery disease genome wide replication and meta analysis (CARDIoGRAM) study: a genome-wide association meta-analysis involving more than 22,000 cases and 60,000 controls. Circ Cardiovasc Genet. 2010;3:475-83.

36. Reilly MP, Li M, He J, et al. Identification of ADAMTS7 a novel locus for coronary atherosclerosis and association of $\mathrm{ABO}$ with myocardial infarction in the presence of coronary atherosclerosis: two genome-wide association studies. Lancet. 2011;377:383-92.

37. - Brautbar A, Ballantyne C, Lawson K, Nambi V, Chambless L, Folsom AR, et al. Impact of adding a single allele in the 9p21 locus to traditional risk factors on reclassification of coronary heart disease risk and implications for lipid-modifying therapy in the Atherosclerosis Risk in Communities Study. Circ Cardiovasc Genet. 2009;2:279-85. This article concerns the addition of 9p21 information to the ARIC risk score and CHD risk classification.

38. Dandona S, Stewart AF, Chen L, Williams K, So D, O'Brien E, et al. Gene dosage of the common variant $9 \mathrm{p} 21$ predicts severity of coronary artery disease. J Am Coll Cardiol. 2010;56:479-86.

39. Shiffman D, Rowland CM, Sninsky JJ, Devlin JJ. Polymorphisms associated with coronary heart disease: better by the score. Curr Opin Mol Ther. 2006;8:493-9. 
40. Davies RW, Dandona S, Stewart AF, Chen L, Ellis SG, Tang WH, et al. Improved prediction of cardiovascular disease based on a panel of single nucleotide polymorphisms identified through genome-wide association studies. Circ Cardiovasc Genet. 2010;3:468-74.

41. Preventive US. Services Task Force Aspirin for the prevention of cardiovascular disease: U.S. Preventive Services Task Force recommendation statement. Ann Intern Med. 2009;150:396-404.

42. - Chasman DI, Shiffman D, Zee RY, Louie JZ, Luke MM, Rowland CM, Catanese JJ, Buring JE, Devlin JJ, Ridker PM Polymorphism in the apolipoprotein(a) gene, plasma lipoprotein (a), cardiovascular disease, and low-dose aspirin therapy. Atherosclerosis. 2009 A;203:371-376. This article reports on the association of aspirin with the LPA polymorphism and risk reduction in the Womens Health Study.

43. Mahley RW. Apolipoprotein E: cholesterol transport protein with expanding role in cell biology. Science. 1988;240:622-30.

44. Bennet AM, Di Angelantonio E, Ye Z, Wensley F, Dahlin A, Ahlbom A, et al. Association of apolipoprotein E genotypes with lipid levels and coronary risk. JAMA. 2007;298:1300-11.

45. Chasman DI, Pare G, Zee RY, et al. Genetic loci associated with plasma concentration of LDL-C, HDL-C, triglycerides, ApoA1, and $\mathrm{ApoB}$ among 6382 caucasian women in genome-wide analysis with replication. Circ Cardiovasc Genet. 2008;1:21-30.

46. Tirot L, Knijff P, Menzel H, et al. ApoE polymorphism and predisposition to coronary heart disease in youths of different european populations. Arterioscler Thromb. 1994;14:1617-24.

47. Zintzaras E, Kitsios GD, Triposkiadis F, Lau J, Raman G. Apo E gene polymorphisms and response to statin therapy. Pharmacogenomics J. 2009;9:248-57.

48. Mega JL, Morrow DA, Brown A, Cannon CP, Sabatine MS. Identification of genetic variants associated with response to statin therapy. Arterioscler Thromb Vasc Biol. 2009;29:1310-5.

49. • Li Y, Iakoubova O, Shiffman D, Devlin J, Forrester J, Superko HR. KIF6 polymorphism as a predictor of risk of coronary events and of clinical event reduction by statin therapy. Am J Card. 2010;106:994-998. This is a review of multiple KIF6 clinical trial studies.

50. Ridker PM, Macfadyen JG, Glynn RJ, Chasman DI. Kinesin-Like Protein 6 (KIF6) polymorphism and the efficacy of rosuvastatin in primary prevention. Circ Cardiovasc Genet. 2011;4(3):312-7.

51. Hopewell JC, Parish S, Clarke R, Armitage J, Bowman L, Hager J, et al. MRC/BHF Heart Protection Study Collaborative Group. No impact of KIF6 genotype on vascular risk and statin response among 18,348 randomized patients in the heart protection study. J Am Coll Cardiol. 2011;57(20):2000-7.

52. Carlson LA. Nicotinic acid: the broad-spectrum lipid drug. A 50th anniversary review. J Intern Med. 2005;258:94-114.
53. Superko HR, McGovern ME, Raul E, Garrett BC. Nicotinic acid has a differential effect on low density lipoprotein subclass distribution in patients classified as LDL pattern A, B, or I. Am J Card. 2004;94:588-94.

54. Zambon A, Deeb SS, Brown BG, et al. Common hepatic lipase gene promoter variant determines clinical response to intensive lipid-lowering treatment. Circulation. 2001;103:792-8.

55. Friedlander Y. Familial clustering of coronary heart disease: a review of its significance and role as a risk factor for the disease. In: Goldbourt U, de Faire U, Berg K, editors. Genetic factors in coronary heart disease. Hingham: Kluwer Academic Publishers; 1994. p. 37-53.

56. Rissanen AM. Familial occurrence of coronary heart disease: effect of age at diagnosis. Am J Cardiol. 1979;44:60-6.

57. AHA Heart Disease and Stroke statistics. 2005 Update. www. americanheart.org

58. Colditz GA, Rimm EB, Giovannucci E, et al. A prospective study of parental history of myocardial infarction and coronary artery disease in men. Am J Cardiol. 1991;67:933-8.

59. Rissanen AM. Familial occurrence of coronary heart disease: effect of age at diagnosis. Am J Cardiol. 1979;44:60-6.

60. Taylor AJ, Bindeman J, Bhattarai S, et al. Subclinical calcified atherosclerosis in men and its association with a family history of premature coronary heart disease in first- and second-degree relatives. Prev Cardiol. 2004;7:163-7.

61. Nasir K, Michos ED, Rumberger JA, et al. Coronary artery calcification and family history of premature coronary heart disease. sibling history is more strongly associated than parental history. Circulation. 2004;110:2150-6.

62. Folsom AR, Kronmal RA, Detrano RC, et al. Coronary artery calcification compared with carotid intima-media thickness in the prediction of cardiovascular disease incidence. The Multi-Ethnic Study of Atherosclerosis (MESA). Arch Intern Med. 2008;168: 1333-9.

63. Clarkson P, Celermajer DS, Powe AJ, Donald AE, Henry RM, Deanfield JE. Endothelium-dependent dilatation is impaired in young healthy subjects with a family history of premature coronary disease. Circulation. 1997;96:3378-83.

64. Kuvin JT, Mammen A, Mooney P, et al. Assessment of peripheral vascular endothelial function in the ambulatory setting. Vasc Med. 2007;12:13-6.

65. - Superko HR, Momary K, Pendyala LK, et al. Firefighters, heart disease, and aspects of Insulin Resistance. The FEMA firefighter heart disease prevention study. J Occ Envir Med. 2011;53:758764. This is the first report of the National Firefighter Heart Disease Prevention Project and coronary calcium rates among professional firefighters. 